University of Nebraska - Lincoln

DigitalCommons@University of Nebraska - Lincoln

$9-1-2003$

\title{
Caveat Relocator: A Practical Relocation Proposal to Save Space and Promote Electronic Resources
}

David C. Tyler

University of Nebraska - Lincoln, dtyler2@unl.edu

Brian L. Pytlik Zillig

University of Nebraska-Lincoln, bzillig1@unl.edu

Follow this and additional works at: https://digitalcommons.unl.edu/libraryscience

Part of the Library and Information Science Commons

Tyler, David C. and Pytlik Zillig, Brian L., "Caveat Relocator: A Practical Relocation Proposal to Save Space and Promote Electronic Resources" (2003). Faculty Publications, UNL Libraries. 123.

https://digitalcommons.unl.edu/libraryscience/123

This Article is brought to you for free and open access by the Libraries at University of Nebraska-Lincoln at DigitalCommons@University of Nebraska - Lincoln. It has been accepted for inclusion in Faculty Publications, UNL Libraries by an authorized administrator of DigitalCommons@University of Nebraska - Lincoln. 


\title{
Caveat Relocator: A Practical Relocation Proposal to Save Space and Promote Electronic Resources
}

\author{
David C. Tyler \\ Brian L. Pytlik Zillig
}

\begin{abstract}
Despite ever-increasing electronic information, space on library shelves continues to be a problem. This article discusses one library's efforts to find space on overcrowded library shelves by moving selected resources to off-site storage and at the same time promoting use of electronic resources, namely the electronic journals that make up the JSTOR database. Issues explored include in-house use of bound periodicals, circulation statistics, interlibrary loan requests, and computer printing vs. photocopying for print titles available through JSTOR. [Article copies available for a fee from The Haworth Document Delivery Service: 1-800-HAWORTH. E-mail address: $<$ docdelivery@haworthpress.com> Website: <http://www.HaworthPress.com> (c) 2003 by The Haworth Press, Inc. All rights reserved.]
\end{abstract}

KEYWORDS. Library storage, JSTOR, electronic resources, collection management, library space, library shelving

David C. Tyler is Assistant Professor and Reference Librarian, University Libraries, University of Nebraska-Lincoln. He holds an AB in English and an MS in LIS from the University of Illinois at Urbana/Champaign, and an MA in English from Bradley University.

Brian L. Pytlik Zillig is Assistant Professor and Digital Initiatives Librarian, University Libraries, University of Nebraska-Lincoln. He holds a BA in English from the University of Nebraska-Lincoln, an MPA from the University of Nebraska at Omaha, and an MLS from Emporia State University.

Technical Services Quarterly, Vol. 21(1) 2003

http://www.haworthpress.com/store/product.asp?sku=J124

(C) 2003 by The Haworth Press, Inc. All rights reserved.

10.1300/J124v21n01_02 
As collections threaten to outgrow their physical plants, many large university and college libraries are moving portions of their holdings to off-site storage facilities. Librarians are consequently required to make tough choices when selecting items to be weeded outright or to be stored. Recently, at the University of Nebraska-Lincoln, liaison librarians were asked to assist in weeding the University Libraries' collections of duplicate titles and to identify little-used items that could be sent to a remote storage facility. Among the usual suggested shelf-crowders-older sets of encyclopedias and older directories-was one previously unconsidered: journal volumes published before 1980 for inactive titles and titles whose subscriptions had been cancelled.

Separately, and serendipitously, liaison librarians were informed by the University Libraries' Collection Development Coordinator that the University's usage statistics for the JSTOR database were rather low. While considering this, the authors wondered if the usage numbers might be low because patrons were unaware of JSTOR or because the older issues of the titles available through JSTOR were rarely used, regardless of format. If the latter possibility was true, then perhaps the titles could be removed from the shelves to offsite storage with little negative effect, for their contents would remain readily available electronically. The older volumes of journals available only in print could thereby remain accessibly and, more importantly for the more obscure titles, browse-ably upon the shelves.

\section{THE PROPOSAL TO MOVE JSTOR TITLES TO STORAGE}

Most library faculty, including the authors, seemed interested but cautious about the proposal to move the older volumes of the JSTOR-available journals to storage. Concerns and objections to the proposal, several of which could be raised at other academic libraries where similar plans were being considered, included: (1) that the bound copies of JSTOR titles do circulate, and that the JSTOR-available volumes are pulled from the shelves far more often than they are checked out of the library, so much more often that removing the volumes to storage would likely lead to many volumes being retrieved from the storage facility; (2) that the JSTOR-available titles comprise too large and too diverse a group to be meaningfully measured as a whole, so some of the JSTOR topical groups are doubtlessly used much more than others and therefore ought not to be moved; (3) that perhaps patrons were unaware of JSTOR and were regularly requesting articles through 
ILL that were available from JSTOR; (4) that printing from JSTOR, even though free of charge at this institution, is more time-consuming than photocopying articles, particularly in libraries still using dot-matrix printers on public computers; and (5) that the removal of the back-files of such important titles from the shelves could cause public relations problems with students and faculty on campus. Some of the above objections have more merit than others and are discussed below.

\section{CIRCULATION}

To obtain some sense of how often it was necessary that the physical volumes of the JSTOR-available titles be on the shelves, the authors decided to look at the titles' circulation numbers, for the number of circulations would indicate how often patrons had accessed a physical volume (so as to take it away from the library) rather than accessed a volume's contents. In tallying the circulations, several of the items available through JSTOR were not included: titles that do not circulate, titles for which the University Libraries does not have physical copies, titles from the new topical groups JSTOR added after this study began, and titles housed at the campuses' branch libraries. The branch-library restriction meant that titles from the JSTOR topical groups Ecology and Mathematics, with the exception of Journal of Symbolic Logic, which does double-duty as a Philosophy title, were not included. Volumes were grouped into five-year runs ending with the 1985-1989 group because of the expectation that titles from the 1990s would not be removed. Table 1 includes the number of titles that had circulating copies within each 5-year grouping and the total number of circulations for each 5-year grouping. For an estimate of how often these titles had to be available on the shelves, the numbers of circulations were averaged by the number of circulating titles, and the numbers of circulations per circulating title were then averaged by the number of years for which data was available, with all averages being rounded to the nearest tenth.

Table 1 presents no great surprises. As one moves from the distant to the more recent past, the total circulations for each of the 5-year groupings of the circulating JSTOR-available titles increase, as do the averages of circulations per circulating title and of circulations per circulating title per year. What is of note, for our purposes, is how low are the average number of circulations per circulating title per year. Over the past 9 years, the most recently published items, those from the 1985-1989 grouping, circulated approximately 3 times per title each 
TABLE 1. Circulations for 1991-2000, with Circulating JSTOR-Available Titles in Five-Year Groupings (Rounded Averages)

\begin{tabular}{|c|c|c|c|c|}
\hline $\begin{array}{l}\text { Five-Year } \\
\text { Groupings }\end{array}$ & $\begin{array}{l}\text { Number of } \\
\text { Circulating Titles }\end{array}$ & $\begin{array}{l}\text { Total } \\
\text { Circulations }\end{array}$ & $\begin{array}{l}\text { Circulations } \\
\text { per Title }\end{array}$ & $\begin{array}{l}\text { Circulations per } \\
\text { Title per Year }\end{array}$ \\
\hline $1835-1839$ & 1 & 0 & 0 & 0 \\
\hline $1840-1844$ & 1 & 1 & 1 & 0.1 \\
\hline $1845-1849$ & 1 & 0 & 0 & 0 \\
\hline $1850-1854$ & 1 & 0 & 0 & 0 \\
\hline $1855-1859$ & 1 & 0 & 0 & 0 \\
\hline $1860-1864$ & 1 & 0 & 0 & 0 \\
\hline $1865-1869$ & 1 & 0 & 0 & 0 \\
\hline $1870-1874$ & 1 & 0 & 0 & 0 \\
\hline $1875-1879$ & 2 & 2 & 1 & 0.1 \\
\hline $1880-1884$ & 2 & 4 & 2 & 0.2 \\
\hline $1885-1889$ & 6 & 0 & 0 & 0 \\
\hline $1890-1894$ & 10 & 7 & 0.7 & 0.1 \\
\hline $1895-1899$ & 12 & 8 & 0.7 & 0.1 \\
\hline $1900-1904$ & 14 & 7 & 0.5 & 0.1 \\
\hline $1905-1909$ & 16 & 8 & 0.5 & 0.1 \\
\hline $1910-1914$ & 17 & 7 & 0.4 & 0 \\
\hline $1915-1919$ & 20 & 27 & 1.4 & 0.2 \\
\hline $1920-1924$ & 21 & 8 & 0.4 & 0 \\
\hline $1925-1929$ & 26 & 17 & 0.7 & 0.1 \\
\hline $1930-1934$ & 30 & 24 & 0.8 & 0.1 \\
\hline 1935 - 1939 & 40 & 25 & 0.6 & 0.1 \\
\hline $1940-1944$ & 44 & 45 & 1 & 0.1 \\
\hline $1945-1949$ & 52 & 73 & 1.4 & 0.2 \\
\hline $1950-1954$ & 57 & 99 & 1.7 & 0.2 \\
\hline $1955-1959$ & 60 & 168 & 2.8 & 0.3 \\
\hline $1960-1964$ & 64 & 235 & 3.7 & 0.4 \\
\hline $1965-1969$ & 71 & 264 & 3.7 & 0.4 \\
\hline $1970-1974$ & 75 & 414 & 5.5 & 0.6 \\
\hline $1975-1979$ & 78 & 584 & 7.5 & 0.8 \\
\hline $1980-1984$ & 79 & 1,088 & 13.8 & 1.5 \\
\hline $1985-1989$ & 79 & 2,139 & 27.1 & 3 \\
\hline
\end{tabular}

year and produced, as a group, approximately 237 circulations each year for the past 9 years (i.e., Number of Titles $\times$ Circulations per Title per Year). Two hundred and thirty-seven circulations may sound like quite a few, certainly more circulations than could be easily dismissed as insignificant, but one ought to keep in mind that these approximate 
yearly totals are for circulations per circulating title and not for circulations per circulating volume. If one were to calculate circulations per circulating volume per year, the numbers would be rather lower: e.g., if one assumes that 1 year equals 1 volume, then the 1985-1989 grouping, which had approximately 237 circulations as a group of titles each year, had approximately 0.6 circulations per volume each year [237 circulations/(79 titles $\times 5$ years/volumes)], or a bit over one circulation for each volume every two years.

So although the JSTOR-available titles have certainly been checked out by patrons, the titles have hardly flown off of the shelves. In fact, if one were to move regressively through Table 1, one would see that the approximate total circulations for each of the 5-year groupings drop precipitously: the approximate yearly circulations for the 1980-84 grouping, 118.5 circulations, are about one half the yearly circulations of the 1985-89 grouping's approximate yearly total of 237; the 1975-79 grouping's yearly circulations, 62.4 circulations, are just a bit more than one half of the 1980-84 grouping's; and so forth. If one were to move by 10 -year groupings through the past 70-years'-worth of JSTOR-available titles, one would find-with the exception of the ratio between the 1980s and the 1970s-that each decade's journals produced as a group around one-half as many circulations each year as the next decade's: the 1930s produced around 7 circulations, the 1940s produced 14.8 circulations, the 1950 s produced 29.4 circulations, the 1960 s produced 54 circulations, and the 1970s produced 107.4 circulations. Unfortunately for those who prefer orderly progressions, the 1970s produced a bit less than one-third of the 355.5 circulations that the 1980 s produced. One might expect, based upon this apparent near-progression, that over the course of the next decade the items from the 1980s should produce around 107.4 circulations per year-the 1970s yearly total for this past decade-and that the items from the 1990s would assume the 1980s' position for this past decade's tally and circulate three times as much as the 1980s will. Regardless of whether or not this occurs, it should be quite clear that the circulating JSTOR-available journals leave the library somewhat infrequently, and one could easily argue that, as they are not often checked out of the library and are also simultaneously available electronically, these volumes, or at least some sizeable portion of these volumes, could profitably be moved to storage without causing patrons any great distress. 


\section{DOES IN-HOUSE USE EXCEED CIRCULATION?}

To discover whether the JSTOR-available volumes were indeed being pulled from the shelves at such a great rate that removing the volumes to storage would be ill-advised, the authors performed a use-study during a period of high use, the spring semester pre-finals rush. During the 4 weeks of April and the first week of May, just 32 circulating JSTOR-available volumes were taken from the shelves, out of an approximate 4,415 available volumes. By way of contrast, during the same period, articles from the on-line counterparts of the circulating JSTOR-available volumes were accessed 2,631 times, and articles were printed out 1,027 times. ${ }^{1}$ Of course, the number of volumes removed from the shelves and the number of articles printed are not directly comparable because it is unknown how many articles were photocopied from the 32 volumes that were taken from the shelves; but the use-counts for the physical volumes are not particularly high, and a comparison of the two modes of access does suggest that patrons are using the electronic copies of these titles as their primary access. Therefore, the first objection to the proposal is probably not a valid one; it is quite likely that most users, when confronted with a choice between using JSTOR or requesting an item from storage, would choose the easier route of using JSTOR.

MINE vs. YOURS:

\section{CIRCULATIONS AMONG THE TOPICAL GROUPS}

To determine whether the circulating titles from some of the JSTOR topical groups (i.e., Education, Philosophy, and so forth) were being used significantly more than others or than the circulating JSTOR-available titles as a whole was quite simple: the data was disaggregated for the 5-year groupings from Table 1 into the JSTOR topical groups for Table 2. As mentioned above, Mathematics, Ecology, and the new collections, such as General Science, were not included. One ought also to keep in mind that several of the titles belong to more than one topical group. If such multi-group titles had abnormally high or low circulations, they could skew the averages of several topical groups, especially those containing few circulating titles. This did not occur in Nebraska's case, but such distortions would be worth watching for elsewhere. Table 2, which contains the disaggregated totals and averages for the 1980-1984 and 1985-1989 five-year groupings 
for each topical group (for almost all topical groups, numbers for the pre-1980 groupings were negligible) ought to put the library faculty's second objection to rest.

As Table 2 reveals, some few of the topical groupings have had a moderately substantial number of circulations over the past 9 years (e.g., with 6.7 circulations per title per year, the 1985-1989 Sociology grouping has had by far the most with 60.4 per title); but most of the topic groups do not (e.g., the 1985-1989 grouping for Asian Studies, with just 0.6 circulations per title per year, has had just 5 circulations per title over the last 9 years). One might consider keeping the 1985-1989 groupings of some of the JSTOR topical groups on the shelves, but one could hardly justify keeping even the 1985-1989 groupings of most of the topical groups on the shelves by virtue of their many circulations, especially when one considers that the grouping with the most circulations, 60.4 circulations per title, has produced less than 1.5 circulations per volume $[60.4$ circulations per title per year $/(9$ titles $\times 5$ volumes $)=$ 1.34 circulations per volume] and a mere 0.15 circulations per volume per year (1.34 circulations per volume/9 years). So it would seem that the argument for particular topical groups is not valid and ought to be dismissed as well.

\section{INTERLIBRARY LOAN REQUESTS}

With respect to the concern that patrons were unaware of JSTOR and were requesting articles from Interlibrary Loan, the authors supposed that if patrons were indeed unaware of these titles' availability through JSTOR, then their ignorance of an alternate means of access would likely manifest in one of three ways: (1) patrons would simply look for other available journals; (2) patrons would complain about journals' not being available and, occasionally, seek assistance (in which case they would be directed to JSTOR); or (3) patrons would file erroneous interlibrary loan requests for articles that they could have accessed through JSTOR. As the frequency of the first two behaviors cannot be easily or accurately assessed, the authors decided to search for evidence of the third. To obtain some sense of how often patrons were unable to locate circulating volumes of JSTOR-available titles on the shelves and were unaware of items' availability through JSTOR, the Interlibrary Loan Office's staff kept track of how often and for what reasons patrons made requests for such items during a peak period of journal usage, November 15th through December 15th, the closing weeks of the fall semester. 
TABLE 2. Circulations for 1991-2000 Disaggregated into JSTOR Topical Groups (Rounded Averages)

\begin{tabular}{|c|c|c|c|c|}
\hline $\begin{array}{l}\text { Five-Year } \\
\text { Groupings }\end{array}$ & $\begin{array}{l}\text { Number of } \\
\text { Circulating Titles }\end{array}$ & $\begin{array}{l}\text { Total } \\
\text { Circulations }\end{array}$ & $\begin{array}{l}\text { Circulations } \\
\text { per Title }\end{array}$ & $\begin{array}{l}\text { Circulations per } \\
\text { Title per Year }\end{array}$ \\
\hline \multicolumn{5}{|c|}{ AFRICAN AMERICAN STUDIES } \\
\hline $1980-1984$ & 5 & 60 & 12 & 1.3 \\
\hline $1985-1998$ & 5 & 136 & 27.2 & 3 \\
\hline \multicolumn{5}{|c|}{ ANTHROPOLOGY } \\
\hline $1980-1984$ & 3 & 55 & 18.3 & 2 \\
\hline $1985-1998$ & 3 & 94 & 31.3 & 3.5 \\
\hline \multicolumn{5}{|c|}{ ASIAN STUDIES } \\
\hline $1980-1984$ & 4 & 7 & 1.8 & 0.2 \\
\hline $1985-1998$ & 4 & 20 & 5 & 0.6 \\
\hline \multicolumn{5}{|l|}{ ECONOMICS } \\
\hline $1980-1984$ & 11 & 261 & 23.7 & 2.6 \\
\hline $1985-1998$ & 11 & 331 & 30.1 & 3.3 \\
\hline \multicolumn{5}{|l|}{ EDUCATION } \\
\hline $1980-1984$ & 2 & 43 & 21.5 & 2.4 \\
\hline $1985-1998$ & 2 & 53 & 26.5 & 2.9 \\
\hline \multicolumn{5}{|l|}{ FINANCE } \\
\hline $1980-1984$ & 4 & 81 & 20.3 & 2.3 \\
\hline $1985-1998$ & 4 & 131 & 32.8 & 3.6 \\
\hline \multicolumn{5}{|l|}{ HISTORY } \\
\hline $1980-1984$ & 14 & 55 & 3.9 & 0.4 \\
\hline $1985-1998$ & 14 & 134 & 9.6 & 1.1 \\
\hline \multicolumn{5}{|l|}{ LITERATURE } \\
\hline $1980-1984$ & 10 & 85 & 8.5 & 0.9 \\
\hline $1985-1998$ & 10 & 216 & 21.6 & 2.4 \\
\hline \multicolumn{5}{|c|}{ PHILOSOPHY } \\
\hline $1980-1984$ & 9 & 96 & 10.7 & 1.2 \\
\hline $1985-1998$ & 9 & 211 & 23.4 & 2.6 \\
\hline \multicolumn{5}{|c|}{ POLITICAL SCIENCE } \\
\hline $1980-1984$ & 9 & 167 & 18.5 & 2.1 \\
\hline $1985-1998$ & 9 & 442 & 49.1 & 5.1 \\
\hline \multicolumn{5}{|c|}{ POPULATION STUDIES } \\
\hline $1980-1984$ & 5 & 12 & 2.4 & 0.3 \\
\hline $1985-1998$ & 5 & 61 & 12.2 & 1.4 \\
\hline \multicolumn{5}{|l|}{ SOCIOLOGY } \\
\hline $1980-1984$ & 9 & 299 & 33.2 & 3.7 \\
\hline 1985 - 1998 & 9 & 544 & 60.4 & 6.7 \\
\hline \multicolumn{5}{|l|}{ STATISTICS } \\
\hline $1980-1984$ & 5 & 19 & 3.8 & 0.4 \\
\hline $1985-1998$ & 6 & 19 & 3.2 & 0.4 \\
\hline
\end{tabular}


As Table $3 \mathrm{a}$ indicates, a mere three requests for three circulating JSTOR-available titles were received during the end-of-semester rush, two for volumes that were unavailable and one because of technical problems. In contrast, JSTOR reported 2,869 article accesses from the JSTOR-available journals with circulating volumes at UNL, with 874 print jobs, for approximately the same period. ${ }^{2}$ To obtain a bit longer perspective, the authors reviewed the data available for the prior sixteen months for erroneous requests.

As Table $3 \mathrm{~b}$ reveals, only 38 requests were made in the entire 16-month period, which comes to less than 2.5 requests per month, an average number of requests slightly lower than the number made during the peak period above. Thus, it would seem, with a mere 2.5 to 3 erroneous requests per month versus several thousand accesses and several hundred print requests, that the patrons who are using the titles are, for the most part, well aware of JSTOR and appear to be comfortable accessing the journals' contents online.

\section{PRINTING vs. PHOTOCOPYING}

The third concern, that printing from JSTOR (even though it has been free of charge at this institution) is more time-consuming than photocopying, and thus patrons prefer to photocopy items, was a reasonable concern, at least for the short-term. As laser printing becomes more readily available, this concern loses its validity. To discover whether photocopying by hand was indeed significantly faster than downloading and printing from JSTOR, a student was enlisted to retrieve from the shelves and photocopy several sets of articles from JSTOR-available volumes

TABLE 3a. ILL Requests for JSTOR-Available Titles, November 15, 1999 to December 15, 1999

\begin{tabular}{lcl}
\multicolumn{1}{c}{ Titles Requested } & Number of Requests & Reason for Request \\
African American Review & 1 & Link would not connect \\
American Literature & 1 & Volume not owned/available \\
MLN & 1 & Volume not owned/available \\
TOTAL REQUESTS: & 3 &
\end{tabular}


TABLE 3b. ILL Requests for JSTOR-Available Titles, June 10, 1998 to October 4, 1999

Titles Requested Number of Requests

\begin{tabular}{|rr}
\hline American Journal of Political Science & 1 \\
American Literature & 1 \\
Anthropology Today & 2 \\
Demography & 3 \\
Ecological Applications & 3 \\
Family Planning Perspectives & 2 \\
Journal of Applied Econometrics & 16 \\
Journal of Black Studies & 3 \\
Journal of Health and Social Behavior & 2 \\
Journal of Negro Education & 1 \\
Philosophical Perspectives & 2 \\
Social Psychology Quarterly & 1 \\
Yale French Studies & 1 \\
TOTAL REQUESTS: & 38
\end{tabular}

and then to attempt to download and print the same sets of articles from JSTOR.

In the first trial, the student was able to retrieve and photocopy a single article of 17 pages in 5 minutes and 56 seconds; in the second trial, she retrieved and copied from 3 different titles 3 articles totaling 56 pages in 14 minutes and 59 seconds; and, in the third trial, she retrieved and copied from 5 different titles 5 articles totaling 99 pages in 25 minutes and 28 seconds. (Note: The main library at the University of Nebraska-Lincoln is so arranged that all of the JSTOR-available volumes included in this study are located on two floors of the same wing of the building, which made them easy to retrieve quickly; the time of retrieval would doubtlessly be greater in libraries with more dispersed collections.) For trial four, the student used JSTOR to find and download the article from the first trial and then print the article, which is when the student ran into trouble: though she easily found the article and was able to download it quickly enough, she had difficulty printing with the dot-matrix printers. On the third try, she was able to find, download, and finally print the 17-page article in 28 minutes and 48 seconds. In all, the student spent nearly 54 minutes printing out a single 17-page article, more time than she had spent on the first three trials combined. 
The fourth trial was then re-performed, this time with a laser printer. The laser printer performed admirably, and the student was able to complete the trial in 6 minutes and 43 seconds, a time comparable to her photocopying effort. As laser printing will soon be more readily available in the University Libraries, this problem will soon be resolved. For libraries where plentiful and affordable laser-printing is readily available and/or where a library's arrangement makes retrieving several separate volumes time-consuming, removing volumes to storage should certainly be considered.

\section{OBJECTIONS BY STUDENTS AND FACULTY-HOW LIKELY?}

While the authors elected not to test the fourth concern-that UNL students and faculty might not accept the removal of titles to storage-at this time, the climate in academic libraries currently seems to be favorable for plans such as this one. In a recent survey of academic library patrons concerning patrons' preferences, Carol Tenopir found that for patrons selecting a database: "[d]espite other cited factors, the most important is the availability of full text"; 3 so, by steering patrons toward JSTOR, one would appear to be encouraging them to discover and use just the sort of resource they appear to prefer. Perhaps even more encouraging is the news from the libraries at Drexel University. As of the year 2000 renewals, Drexel's journal collection consisted of 800 titles in print and 4,951 titles available only in electronic format, ${ }^{4}$ a rather radical shift toward electronic-only access; yet student and faculty response appears to be positive: a short run of at-the-door and online surveys conducted at Drexel indicate that, so far, levels of user satisfaction with both formats are nearly equal. ${ }^{5}$ The authors' proposal to move to storage old runs of journals available in two formats is considerably less radical than what the librarians at Drexel, in making 86 percent of their journal collection electronic, have done.

\section{CONCLUSION}

Thus, it would seem that when a library is faced with overcrowding on the shelves, a proposal to remove the older volumes of the JSTOR titles to storage would be a winning one. A large body of little-circulated materials-in Nebraska's case just over 743 feet of shelf space (of course, other libraries will save different amounts of space depending 
upon their holdings)-could be moved without removing access to those materials' contents, and the library would still enjoy the full advantages of being a JSTOR library. As enumerated by William G. Bowen, conceiver of JSTOR, in his article "How Libraries Can Help to Pay Their Way in the Future," authorized users would continue to be able to access the journals from standard PC equipment at any time and from any networked location; the journals, barring natural and/or man-made disaster, would continue to be available at all times and for simultaneous uses; and their electronically available contents would always be available in pristine condition. ${ }^{6}$ In addition, removing the older volumes from the shelves would save them from the wear and tear that comes from being handled by patrons and being shifted about by library staff. The removal of the volumes would also allow one to compress one's collection in an area where growth will be constant and predictable-one would not expect any of the journals' publishers to suddenly issue twelve volumes in one year-and thereby ease pressures in those areas of one's collection where growth is more sporadic and unpredictable.

Despite the many benefits of a plan such as this, it appears that libraries are only slowly considering their JSTOR journals when making storage plans. A 1999 survey by JSTOR found that just 20 percent of respondents had moved journals to remote storage and that a mere additional 24 percent had plans to do so. ${ }^{7}$ At the University of Nebraska-Lincoln, this proposal, while not accepted wholly, has resulted in additional laser printers for the public areas as well as for several library faculty with very crowded shelves in their liaison areas to consider moving their JSTOR-available titles. JSTOR provides a rare opportunity for libraries faced with collections that have outgrown their buildings: a way to remove items from the shelves without removing them from the readily-accessible collection. In light of what has been discovered about these titles' use, the authors highly recommend that libraries take advantage of the benefits and opportunities that JSTOR provides.

\section{NOTES}

1. JSTOR, "Statistics for 2000/04: Accesses from Your Site" and "Statistics for 2000/05: Accesses from Your Site" [generated computer files]. Ann Arbor, MI, 2000 [accessed July 2000]. Tables available at: <http://stats.jstor.org/>. Access may be limited to participating institutions. Contact JSTOR User Services for information.

2. JSTOR, "Statistics for 1999/11: Accesses from Your Site" and "Statistics for 1999/12: Accesses from Your Site" [generated computer files]. Ann Arbor, MI: JSTOR, 2000 [accessed July 2000]. Tables available at: <http://stats.jstor.org/>. Ac- 
cess may be limited to participating institutions. Contact JSTOR User Services for information.

3. Carol Tenopir, "Database Use in Academic Libraries," Library Journal 124, no. 8 (May 1, 1999): 36, 38.

4. Carol Hansen Montgomery and JoAnne L. Sparks. "The Transition to an Electronic Journal Collection: Managing the Organizational Changes." Serials Review 26, no. 3 (2000): 4-18.

5. Ibid., 14-15.

6. William G. Bowen. "How Libraries Can Help to Pay Their Way in the Future." Logos 7. no. 3 (1996): 1-5.

7. William G. Bowen. "The Academic Library in a Digitized, Commercialized Age: Lessons from JSTOR.” (paper presented at the ALA Midwinter Participants' Meeting [based on Romanes Lecture, delivered at Oxford University, October 17, 2000] Washington, D.C., January 14, 2001). Available at: <http://www.jstor.org/about/bowen.html>.

Received for review: August 13, 2002 Accepted for publication: September 17, 2002

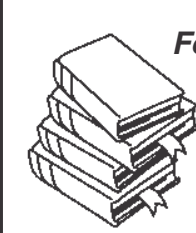

For FACULTYIPROFESSIONALS with journal subscription recommendation authority for their institutional library . . .

If you have read a reprint or photocopy of this article, would you like to make sure that your library also subscribes to this journal? If you have the authority to recommend subscriptions to your library, we will send you a free complete (print edition) sample copy for review with your librarian.

1. Fill out the form below and make sure that you type or write out clearly both the name of the journal and your own name and address. Or send your request via e-mail to docdelivery@haworthpress.com including in the subject line "Sample Copy Request" and the title of this journal.

2. Make sure to include your name and complete postal mailing address as well as your institutional/agency library name in the text of your e-mail.

[Please note: we cannot mail specific journal samples, such as the issue in which a specific article appears. Sample issues are provided with the hope that you might review a possible subscription/e-subscription with your institution's librarian. There is no charge for an institution/campus-wide electronic subscription concurrent with the archival print edition subscription.]

$\square$ YES! Please send me a complimentary sample of this journal:

(please write complete journal title here-do not leave blank)

I will show this journal to our institutional or agency library for a possible subscription. Institution/Agency Library:

Name:

Institution:

Address:

City: __ State: __ Zip:

Return to: Sample Copy Department, The Haworth Press, Inc.,

10 Alice Street, Binghamton, NY 13904-1580 